\title{
NKX3.1 contributes to $S$ phase entry and regulates DNA damage response (DDR) in prostate cancer cell lines
}

\author{
Burcu Erbaykent-Tepedelen ${ }^{\mathrm{a}}$, Besra Özmen ${ }^{\mathrm{a}}$, Lokman Varisli ${ }^{\mathrm{a}}$, Ceren Gonen-Korkmaz ${ }^{\mathrm{b}}$, \\ Bilge Debelec-Butuner ${ }^{\mathrm{a}, \mathrm{c}}$, Hamid Muhammed Syed ${ }^{\mathrm{a}}$, Ozgur Yilmazer-Cakmak ${ }^{\mathrm{d}}$, Kemal Sami Korkmaz ${ }^{\mathrm{a}, *}$ \\ a Ege University, Engineering Faculty, Department of Bioengineering, Cancer Biology Laboratory, Faculty of Pharmacy, Bornova, Izmir, Turkey \\ ${ }^{\mathrm{b}}$ Ege University, Faculty of Pharmacy, Department of Pharmacology, Bornova, Izmir, Turkey \\ ' Ege University, Faculty of Pharmacy, Department of Biotechnology, Bornova, Izmir, Turkey \\ ${ }^{\mathrm{d}}$ Izmir Institute of Technology, Biotechnology and Bioengineering Central Research Laboratories, Gulbahce, Izmir, Turkey
}

\section{A R T I C L E I N F O}

\section{Article history:}

Received 31 August 2011

Available online 14 September 2011

\section{Keywords:}

DNA damage response

Topoisomerase inhibitor CPT-11

Prostate cancer

$\gamma \mathrm{H} 2 \mathrm{AX}^{(\mathrm{S} 139)}$ foci

pATM $^{(S 1981)}$

NKX3.1

\begin{abstract}
A B S T R A C T
NKX3.1 is an androgen-regulated homeobox gene that encodes a tissue-restricted transcription factor, which plays an important role in the differentiation of the prostate epithelium. Thus, the role of NKX3.1 as a functional topoisomerase I activity enhancer in cell cycle regulation and the DNA damage response (DDR) was explored in prostate cancer cell lines. As an early response to DNA damage following CPT-11 treatment, we found that there was an increase in the $\gamma \mathrm{H}_{2} \mathrm{AX} \mathrm{X}^{(\mathrm{S} 139)}$ foci number and that total phosphorylation levels were reduced in PC-3 cells following ectopic NKX3.1 expression as well as in LNCaP cells following androgen administration. Furthermore, upon drug treatment, the increase in $\mathrm{ATM}^{(\mathrm{S1981)}}$ phosphorylation was reduced in the presence of NKX3.1 expression, whereas DNA-PKcs expression was increased. Additionally, phosphorylation of $\mathrm{CHK}_{2}{ }^{(\mathrm{T68})}$ and $\mathrm{NBS}^{(\mathrm{S} 343)}$ was abrogated by ectopic NKX3.1 expression, compared with the increasing levels in control PC-3 cells in a time-course experiment. Finally, NKX3.1 expression maintained a high cyclin D1 expression level regardless of drug treatment, while total $\gamma \mathrm{H}_{2} \mathrm{AX}^{(\mathrm{S} 139)}$ phosphorylation remained depleted in PC-3, as well as in LNCaP, cells. Thus, we suggest that androgen regulated NKX3.1 maintains an active DDR at the intra $\mathrm{S}$ progression and contributes to the chemotherapeutic resistance of prostate cancer cells to DNA damaging compounds.
\end{abstract}

(c) 2011 Elsevier Inc. All rights reserved.

\section{Introduction}

Although androgen ablation therapy for prostate cancer leads to decreased tumor cell proliferation and regression of tumor size [1], the disease recurs within 2-3 years in most organ confined prostate cancer cases $[2,3]$. This recurrence may be due to developing tumors retaining functional androgen receptors (AR), which allow the tumors to respond to AR signaling events [4,5]. In these tumors, ARs can be induced via promiscuous growth factors, which results in transactivation of androgen-regulated genes that might significantly affect tumor progression. The NKX3.1 gene is upregulated by androgens via an AR dependent mechanism in normal prostate epithelium [6,7]. It encodes a prostate- and testis-specific nucleoprotein with two conserved domains in its wild type isoform (234 aa long). These domains are required for the interaction of NKX3.1 with specific nuclear proteins and DNA [8]. The binding of NKX3.1 negatively modulates AR transcription (putatively via target promoter association) and subsequent signaling events in pros-

\footnotetext{
* Corresponding author.

E-mail address: ks_korkmaz@yahoo.com (K.S. Korkmaz).
}

tate cells. Its expression also contributes to both cell cycle and cell death machinery by increasing p53 acetylation and through subsequent stabilization of the MDM2-dependent mechanism [9]. However, as part of the Groucho complex, NKX3.1 is required to repress transcription with its loss resulting in prostatic epithelial dysplasia and benign hyperplasia of the rat prostate $[10,11]$. Ouyang et al., have shown that NKX3.1 suppresses tumor initiation by protecting the cell against oxidative damage via transcriptional regulation of the pro-oxidant enzyme levels [12,13]. TOPORS, a strong E3 ubiquitin ligase, promotes proteasomal degradation of NKX3.1 through direct interaction, predisposing cells to oncogenic transformation by providing an irreversible growth advantage as the first steps in prostate carcinogenesis [14]. Recently, it has been reported that NKX3.1 relocates to the nucleus and enhances the cleavage and re-ligation abilities of the topoisomerase I (topo I) enzyme through direct association $[15,16]$. ATM and ATR activities are influenced by NKX3.1 expression, which protects cells against IR- and mitomycin C-induced DNA damage [17]. Thus, the DNA damage response is more efficient in cells in the presence of NKX3.1 expression; this report provides useful insights into our understanding of the DDR as well as therapy resistance of LNCaP cells upon DNA damage. We 
hypothesize that NKX3.1 basal expression protects cells against oxidative damage and/or maintains the constitutive DNA damage response in prostate cells through an unknown mechanism and thus is required to suppress cancer initiation in prostate epithelia [12,13].

In our study, CPT-11 (a semi-synthetic form of camptothecin) was used as a damage inducer to generate "double strand" DNA breaks (DSBs) during replication. In androgen-responsive (native NKX3.1 expressing) LNCaP and in the hormone-independent prostate cell line PC-3 (forced NKX3.1 expression), drug induced $\mathrm{H}_{2} \mathrm{AX}^{(\mathrm{S} 139)}$ and $\mathrm{ATM}^{(\mathrm{S} 1981)}$ phosphorylation, as well as foci formations were investigated after short ( 0.5 and $4 \mathrm{~h}$ ) and long ( $24 \mathrm{~h})$ exposures of CPT-11. Thus, we determined that the phosphorylation status and the foci number are regulated in prostate cells by NKX3.1 expression in a time-dependent manner. Therefore, we propose that as a hormone responsive factor NKX3.1 suppresses the initiation of prostate cancer by deregulating the oxidative stress and cell growth, which, upon DNA damage, contributes to therapy resistance by promoting repair response and cyclin D1 expression in castration resistant prostate tumors. Considering this evidence, NKX3.1 might be an important regulator of the DDR in the prostate epithelium for maintaining genome fidelity against cancer progression.

\section{Materials and methods}

\subsection{Constructs and antibodies}

NKX3.1 cDNA (accession number AF249669) was used for the construction of pcDNA4-NKX3.1 wild type (234 aa) (Invitrogen, US) [7]. ATM, pATM ${ }^{(\mathrm{S1981})}$, RAD50, and Cyclin D1 mouse monoclonal, and DNA-PK rabbit polyclonal antibodies were purchased from Santa Cruz Biotechnology Inc. (Bergheim, Germany). $\gamma \mathrm{H} 2 \mathrm{AX}^{(\mathrm{S} 139)}$ mouse monoclonal antibody was purchased from Millipore (US). The NKX3.1 rabbit polyclonal antibody was a kind gift from Dr. Fahri Saatcioglu, from University of Oslo, Norway, and the $\beta$-actin antibody (Sigma) was a kind gift from Dr. Buket Kosova of Ege University, Izmir, Turkey. Alexa-fluor488- and 594-conjugated secondary antibodies were also purchased from Invitrogen (Carlsbad, US). Primary and secondary antibodies were used at a concentration range of 0.2 to $2 \mu \mathrm{g} / \mathrm{ml}$.

\subsection{Propagation and androgen induction}

Androgen-responsive LNCaP cells (passage number 10-25) were propagated in RPMI1640 (Invitrogen, UK) medium supplemented with $10 \%$ heat-inactivated FBS (Invitrogen, UK). Cells were serum starved in the presence of $2 \%$ for $48 \mathrm{~h}$ and $0.5 \%$ for an additional $24 \mathrm{~h}$ in CT-FBS containing RPMI1640. R1881 $\left(10^{-8} \mathrm{M}\right)$ inductions were performed for $24 \mathrm{~h}$, while the cells were maintained in serum-starved conditions $[7,18,19]$. Irinotecan (hereafter termed CPT-11; Campto $\left.{ }^{\circledR}\right)(10 \mu \mathrm{g} / \mathrm{ml})$ was used in all treatments for an additional $0.5,4$ or $24 \mathrm{~h}$ after androgen treatment.

\subsection{NKX3.1 transfection}

PC-3 cells were propagated in DMEM/Ham's F12 medium (Invitrogen, UK), supplemented with 5\% FBS, and transfection was performed using Fugene HD (Roche, Germany) according to manufacturer's recommendations. Briefly, $3 \mu \mathrm{l}$ of Fugene HD was dissolved in $100 \mu \mathrm{l}$ of media and incubated for $5 \mathrm{~min}$. Next, $1 \mu \mathrm{g}$ of pcDNA4-NKX3.1 DNA was diluted into the mixture, incubated for $15 \mathrm{~min}$, and then applied to cells grown in $55 \mathrm{~mm}$ tissue culture flasks drop-wise. Cells were treated for the appropriate time and harvested for further studies.

\subsection{Immunoblot}

Cells were lysed with ice-cold modified RIPA buffer (1\% Nonidet P-40, $50 \mathrm{mM}$ Tris $\mathrm{HCl} \mathrm{pH}$ 7.4, 0.25\% Na-deoxycholate, $150 \mathrm{mM}$ $\mathrm{NaCl}$ ), including $1 \mathrm{mM} \mathrm{NaF}, 1 \mathrm{mM}$ EDTA, $1 \mathrm{mM} \mathrm{Na} 3 \mathrm{VO} 4$, and complete protease and phosphatase inhibitor cocktails (Roche, Germany) unless otherwise indicated. Protein separation was performed using 6-15\% SDS-PAGE gels and immobilized onto PVDF membranes (Amersham, UK and/or SantaCruz, Germany) using a wet transfer blotter. Briefly, membranes were blocked using TBS$\mathrm{T}$ (Tris-Base-Saline containing $0.1 \%$ Tween 20 ) containing either $5 \%$ skim milk (w/v) or $1 \%$ BSA for anti-phospho-antibodies. Antibody incubations were performed using TBS-T containing 0.5\% dry milk for $1 \mathrm{~h}$ at RT or overnight at $4{ }^{\circ} \mathrm{C}$. Membranes were developed using $2 \mathrm{ml} \mathrm{ECL}$ plus reagent (Amersham, UK) for $5 \mathrm{~min}$ and were photographed using Kodak X-ray films in a dark room.

\subsection{Immunofluorescence (IF) labeling and microscopy}

For the detection of $\gamma \mathrm{H} 2 \mathrm{AX}{ }^{(\mathrm{S} 139)}$ foci and NKX3.1 expression, cells were grown on cover slips, on which transfection and treatment were performed. Cells were rinsed in PBS and fixed with $4 \%$ paraformaldehyde for $1 \mathrm{~h}$ at RT. Cells were then permeabilized with $0.2 \%$ triton X-100-containing PBS and blocked for 5 min using $1 \%$ BSA in PBS buffer before incubation with primary antibodies. Antibodies were added for $1 \mathrm{~h}$, and samples were washed with PBS twice. Secondary antibody incubations were performed at RT for $20 \mathrm{~min}$ using Alexa-Fluor488/594 (anti-mouse) or AlexaFluor594/488 (anti-rabbit) antibody (Invitrogen, USA). Finally, cells were washed four times with PBS, mounted in $30 \%$ glycerol-PBS containing DAPI $(0.5 \mu \mathrm{g} / \mathrm{ml})$, and analyzed immediately using a Leica DMIL fluorescent microscope (Leica, Germany). Images were captured using the Leica image software (LAS).

\subsection{Cell growth assay}

The xCELLigence System (Roche) for real-time cell analysis of impedance-based signals was used for the quantitative determination of cell proliferation. PC-3 cells were transfected with vector or the full length NKX3.1 expression plasmid, trypsinized $24 \mathrm{~h}$ after transfection and plated into 96-well plates at three different densities $\left(2,4,8 \times 10^{3}\right.$ cells/well). LNCaP cells were induced with $\mathrm{R} 1881$, and cells were grown for $24 \mathrm{~h}$ post transfection/induction and treated with CPT- 11 . The decreasing impedance was measured in real time every $30 \mathrm{~min}$ according to the manufacturer's instructions (xCELLigence, Roche, Germany) and plotted as growth rate.

\subsection{Flow cytometry and analysis}

Cell cycle distribution of $\gamma \mathrm{H}_{2} \mathrm{AX}^{(\mathrm{S} 139)}$ and $\mathrm{pATM}^{(\mathrm{S} 1981)}$ was studied using flow cytometry following CPT-11 treatment in androgentreated LNCaP or NKX3.1 transfected PC-3 cells using a FACSCanto (BD Biosciences, USA). Briefly, after transfection and/or treatment, cells were collected into PBS and were fixed with $100 \%$ cold $\left(-20^{\circ} \mathrm{C}\right)$ ethanol in a drop-wise manner. Next, cells were labeled with specific $\left(\gamma \mathrm{H} 2 \mathrm{AX}^{(\mathrm{S} 139)}\right.$ and/or NKX3.1 antibody at a 1:250 or $1: 500$ dilution, respectively) and secondary antibody conjugated with Alexa-flour 488 (1:1000) as described above. Bivariate readings were performed subsequent to PI staining, and $\gamma \mathrm{H} 2 \mathrm{AX}{ }^{(\mathrm{S} 139)}$ levels were plotted versus DNA content using the FacsDiva 5.0.3 software.

\subsection{Image analysis and statistical calculations}

Image J software was used to perform IF counts and measurements [20]. Expression densities were measured for each nucleus, 
and the number of foci was counted. (1) The expression level and/ or average foci counts were classified into expression groups depending on density, which were given in Table 1. (2) Standard deviation and (3) p values were provided in each Fig. legend. Where necessary, p values were calculated using Kruskal-Wallis and Mann-Whitney tests among groups and in between pairs, respectively.

\section{Results and discussion}

Hormone-responsive tumors, including those of the breast, uterus and prostate were recently reported to have alterations in the expression of hormone responsive factors. These factors might have roles in maintaining genome stability [21-24]. We report that functional NKX3.1, the prostate- and testis-restricted homeoboxcontaining factor, activates DNA damage response upon topoisomerase I inhibition in prostate cells.

\subsection{CPT-11-mediated $\gamma H 2 A X$ foci formation is lost in NKX3.1- expressing cells during the $S$ phase}

We investigated the role of ectopic expression of NKX3.1 in DNA repair. When PC-3 cells were treated with CPT- 11 for $0.5,4$ or $24 \mathrm{~h}$ in immunofluorescence studies, the cells exhibited uniform $\gamma \mathrm{H} 2 \mathrm{AX}{ }^{(\mathrm{S} 139)}$ foci formations, with the number of foci positively correlated with increasing DNA content and the time of exposure (Fig. 1A). As the number of foci per nucleus was variable, cells were grouped by means of $\gamma \mathrm{H} 2 \mathrm{AX}{ }^{(\mathrm{S139})}$ foci number, as shown in Table 1 $(<1,1-20,20-50$ and $>50$ foci/nucleus $)$. In the absence of NKX3.1 expression, the baseline number of foci was $<1$ and increased by 38 and $54 \%$ at 0.5 and $4 \mathrm{~h}$ of CPT- 11 treatment, respectively. The ectopic expression of NKX3.1 significantly reduced cells with foci by 34 and $31 \%$ after 0.5 and $4 \mathrm{~h}$ of CPT- 11 treatment, respectively (Fig. 1B). The average number of foci for control, vector and NKX3.1-expressing cells were $100 \pm 17,86 \pm 26$ and $15 \pm 14$, respectively (Fig. 1C). Control and vector-transfected cells (number of cells; $n=8$ and 66 , respectively) had no significant difference in foci number regardless of CPT-11 treatment $\left({ }^{*} p=0.058\right)$. NKX3.1expressing cells had decreased (average) foci numbers compared with the vector $\left({ }^{* *} p<0.01\right)$. NKX3.1-expressing cells have a lower proliferation rate, and CPT- 11 treatment further decreased the growth rate of both control and NKX3.1-expressing cells. These data suggest that NKX3.1-positive cells are prone to develop chemo-resistance to therapy depending on exposure time and dose. Moreover, using flow cytometry, $S$ phase cells had higher $\gamma \mathrm{H}_{2} \mathrm{AX}^{(\mathrm{S} 139)}$ and $\mathrm{pATM}^{(\mathrm{S} 1981)}$ phosphorylations (highest at $24 \mathrm{~h}$ ) compared with $S$ phase cells in the presence of NKX3.1 following CPT-11 treatments (Suppl. Fig. 1). Because PC-3 cells accumulated more in the intra S phase upon treatment (30\% at $24 \mathrm{~h}$ ), the arrest

\section{Table 1}

When the counts were performed using image J software from captured images using immunofluorescence microscopy, cells were grouped into four different categories according to intensity observed (mean expression per cell). The $\gamma \mathrm{H} 2 \mathrm{AX}^{(\mathrm{S} 139)}$ foci count and cyclin D1 expression are categorized (average expression values from Fig. $1 \mathrm{~B}$ and $\mathrm{C}$ and Suppl. Fig. 2B and C) and plotted in terms of groups (Fig. 1B and Suppl. Fig. 2B). ( $\beta$-actin was used as a loading control. Western blots were performed at least twice for each time course and Kruskal-Wallis and $t$-test statistics were applied where appropriate).

\begin{tabular}{llllll}
\hline \multirow{2}{*}{ Categories } & \multicolumn{2}{l}{ NKX3.1 and Cyclin D1 } & & $\gamma \mathrm{H} 2 \mathrm{AX}$ \\
\cline { 2 - 3 } \cline { 5 - 6 } \cline { 5 - 6 } & Mean values & $\%$ of expression & & Mean values & $\%$ of expression \\
\hline+++ & $40-60$ & $65-100$ & & $15-30$ & $50-100$ \\
++ & $20-40$ & $30-65$ & & $10-15$ & $30-50$ \\
+ & $1-20$ & $1-30$ & & $1-10$ & $1-30$ \\
- & $<1$ & 0 & $<1$ & 0 \\
\hline
\end{tabular}

observed at NKX3.1 expression was significantly suppressed (reduced to $14 \%$ ) (Fig. 2A); furthermore, $\gamma \mathrm{H} 2 \mathrm{AX}^{(\mathrm{S} 139)}$ and $\mathrm{pATM}^{(\mathrm{S} 1981)}$ were decreased (Suppl. Fig. 1 and Fig. 2B). Overall, the data suggest that NKX3.1 has a regulatory role for genome maintenance in prostate cells through activation of the DNA damage response.

\subsection{DDR mediators are influenced in a time-dependent manner by ectopic NKX3.1 expression}

To investigate the role of NKX3.1 in DDR, we studied $\mathrm{H}_{2} \mathrm{AX} \mathrm{X}^{(\mathrm{S} 139)}$, DNA-PKcs, ATM ${ }^{(\mathrm{S} 1981)}, \mathrm{NBS}^{(\mathrm{S} 343)}$ and $\mathrm{CHK}^{(\mathrm{T} 68)}$ expression/phosphorylation in PC-3 cells in the presence or absence of NKX3.1 expression. Control cells responded to CPT-11 treatment, as observed by the increased phosphorylation levels of $\mathrm{H}_{2} \mathrm{AX}^{(\mathrm{S} 139)}$, $\mathrm{ATM}(\mathrm{S} 1891), \mathrm{NBS1}^{(\mathrm{S} 343)}$ and CHK2 ${ }^{\text {(T68) }}$. In comparison, NKX3.1 cells had higher constitutive baseline levels of phosphorylation, which were reduced in a time-dependent manner upon CPT-11 treatment (Fig. 3A and B), suggesting that the DDR was constitutively activated upon NKX3.1 expression in the PC-3 prostate cells. Phosphorylations of $\mathrm{CHK}^{(\mathrm{T} 68)}$ and $\mathrm{NBS} 1^{\text {(S343) }}$ consistently followed changes of pATM $^{(\mathrm{S} 1981)}$, while the expression of the CHK2 was not induced until $4 \mathrm{~h}$ and DNA-PKcs remained constant in the absence of NKX3.1, whereas they were profoundly increased in the presence of NKX3.1 upon CPT-11 (Fig. 3). Additionally, cyclin D1 expression was found decreased, leading to arrest of cell growth in the absence of NKX3.1 (Fig. 2A), which was restored with transient expression of NKX3.1 (Fig. 3 and Suppl. Fig. 2A).

The nuclear localized cyclin D1 expression was measured (intensity) using image J software from microscopic images. The percentage of cells expressing cyclin D1 (with a mean intensity $>40$ ) increased from 26 to 34\% upon NKX3.1 expression. Upon treatment with CPT-11, however, the proportion of cyclin D1 expressing cells increased from 17 to $42 \%$ and 20 to $44 \%$, respectively, at both the 4 and $24 \mathrm{~h}$ time points compared to controls (Suppl. Fig. 2B). Therefore, we hypothesize that DDR in native PC-3 cells correlates with the DNA damage status, depending on exposure time, where the $\gamma \mathrm{H} 2 \mathrm{AX}{ }^{(\mathrm{S139})}$ level is kept low and nuclear localized cyclin D1 expression is maintained at a high level by NKX3.1 expression (Suppl. Fig. 2C). This result may be the consequence of the NKX3.1-mediated enhancement of topoisomerase I re-ligation ability and/or the interaction of HDAC1, which have been previously reported [10]. These results demonstrate that, upon CPT-11 mediated damage, the repair cascade works more efficiently in cells expressing NKX3.1, whose expression is tightly regulated via androgens in normal prostate, prostate cancer and hormone refractory prostate tumors.

\subsection{Androgen induction leads to loss of $\gamma H 2 A X^{(S 139)}$ foci formation}

The occurrence of $\gamma \mathrm{H} 2 \mathrm{AX} \mathrm{X}^{(\mathrm{S} 139)}$ foci was repeatedly observed as non-uniformly distributed in LNCaP cells in the absence of androgen. Following drug treatment, these cells exhibited intense $\gamma \mathrm{H} 2 \mathrm{AX}^{(\mathrm{S} 139)}$ foci, with a significant increase in the number of foci per nucleus and a uniform distribution (Fig. 4A). When cells were treated with the synthetic androgen R1881, the foci formations disappeared. Moreover, when cells were treated with CPT-11 (for 4 or $24 \mathrm{~h}$ ) in addition to androgen, the foci formations decreased in cells in the presence of NKX3.1 (dashed circles in Fig. 4). These data suggest that the loss of foci formation is related to androgens, and perhaps to NKX3.1, in LNCaP cells.

Although androgen-responsive gene expression is thought to be influenced by androgens in all cells evenly [7-9], the cells $(<1 \%)$ that have a low expression level of NKX3.1 exhibited intense foci following drug treatment ( 9 and 12\% for 4 and 24 h, respectively; marked with continuous circles in Fig. 4A). Hence, this is a moderate event in LNCaP cells as they are grown in culture without 
A

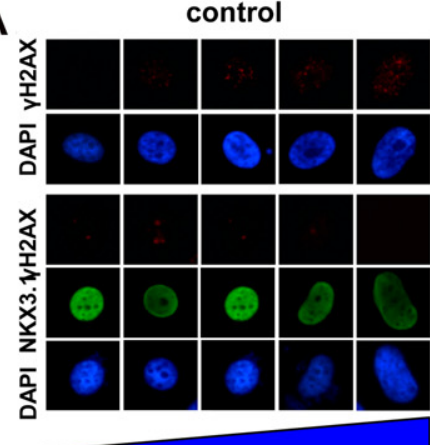

B

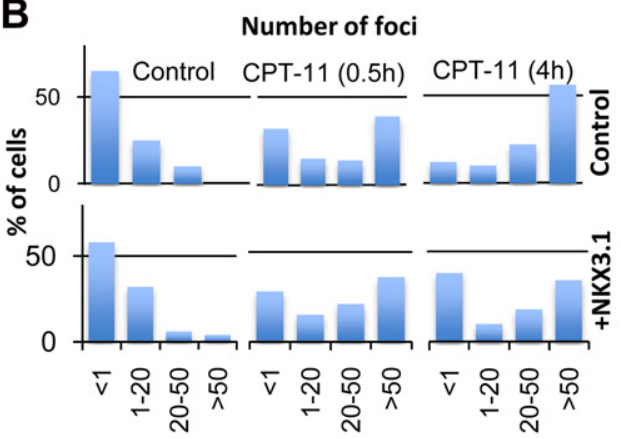

CPT-11 (0.5 hr)

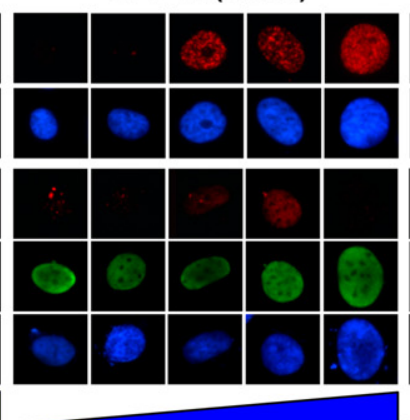

DNA content

C

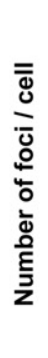

CPT-11 (4 hrs)
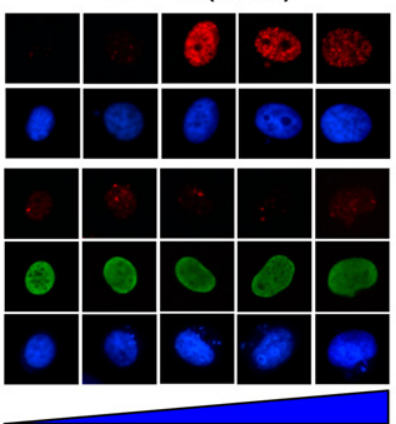

CPT-11 (24 hrs)
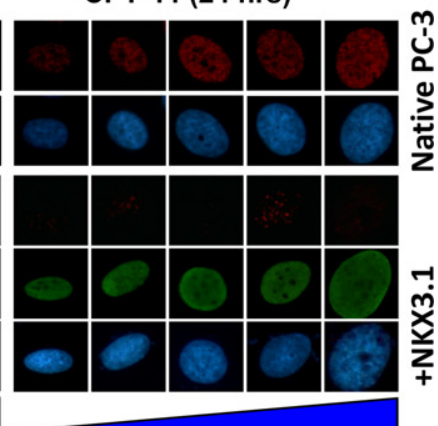

\section{ن̀n

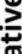 \\ 啇}

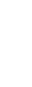
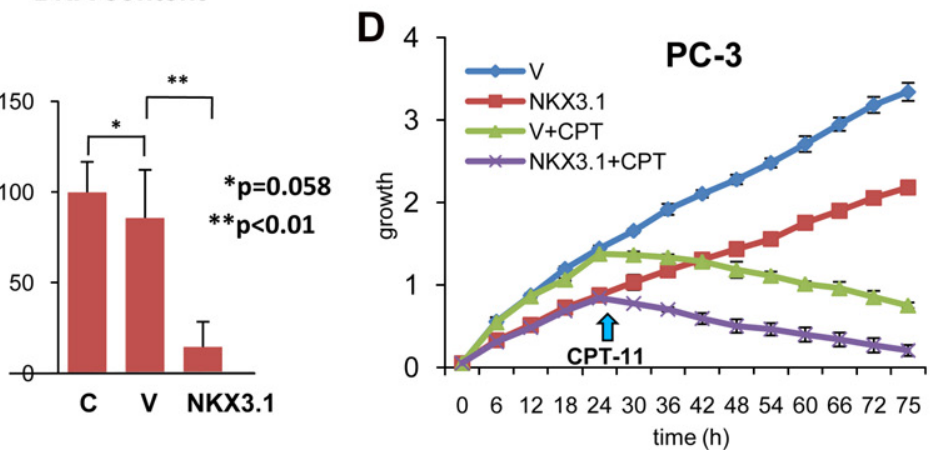

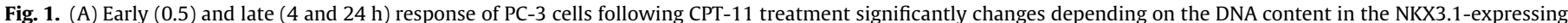

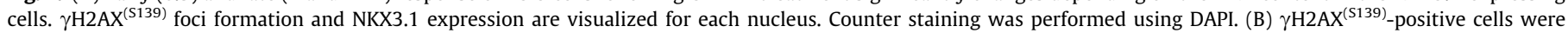

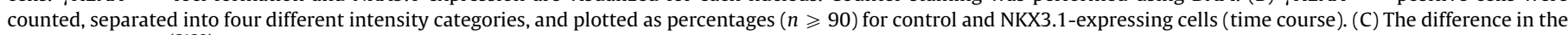

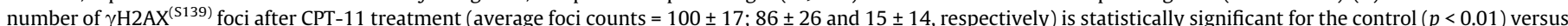

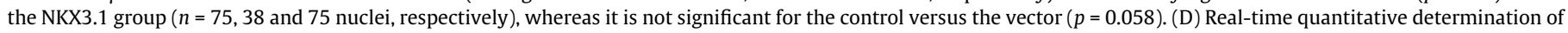

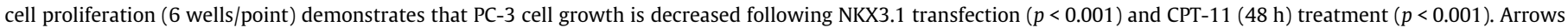
indicate the time that the treatments were performed.
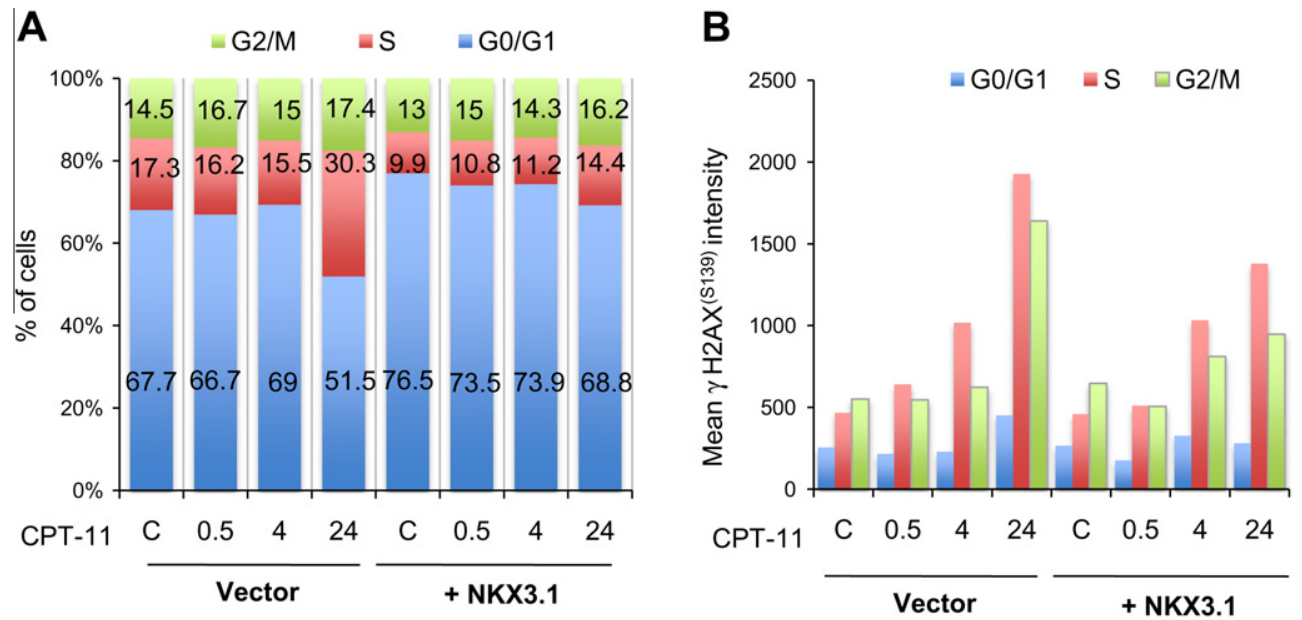

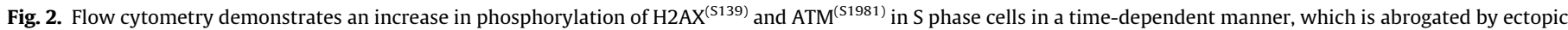

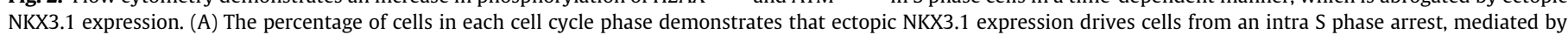
CPT-11, and (B) NKX3.1 expression results in a significant decrease in phosphorylation levels of H2AX $\mathrm{X}^{(\mathrm{S} 139)}$ and $\mathrm{ATM}^{(\mathrm{S} 1981)}$ in all phases of the cell cycle.

androgens, and subsequent androgen treatment results in a substantial decrease in foci formation, leading to an increase in the growth rate. We consistently observed that the LNCaP growth rate slows for $18 \mathrm{~h}$ after androgen administration, which may be related to either morphological alterations or repair activation, resulting in an increased growth rate (as measured using impedance values). Although no difference was observed after $4 \mathrm{~h}$ of treatment using flow cytometry (Suppl. Fig. 4A), the real-time growth assay demonstrated that there was a significant $(p<0.01)$ arrest with CPT-11 treatment in LNCaP cells, regardless of androgen treatment (Fig. 4B). In the presence of androgens, $\gamma \mathrm{H} 2 \mathrm{AX}(\mathrm{S} 139)$ phosphorylation decreased in the $\mathrm{G} 1$ phase, suggesting that cells can tolerate the DNA damage in G1/S transition, and progress through the cell cycle (Fig. 4B).

To determine if the $\gamma \mathrm{H} 2 \mathrm{AX}^{(\mathrm{S} 139)}$ phosphorylation status is related specifically to androgens, we included estrogen treatment in our study. While androgen administration decreased the number of $\gamma \mathrm{H} 2 \mathrm{AX}{ }^{(\mathrm{S} 139)}$ foci and the phosphorylation status, estrogen 

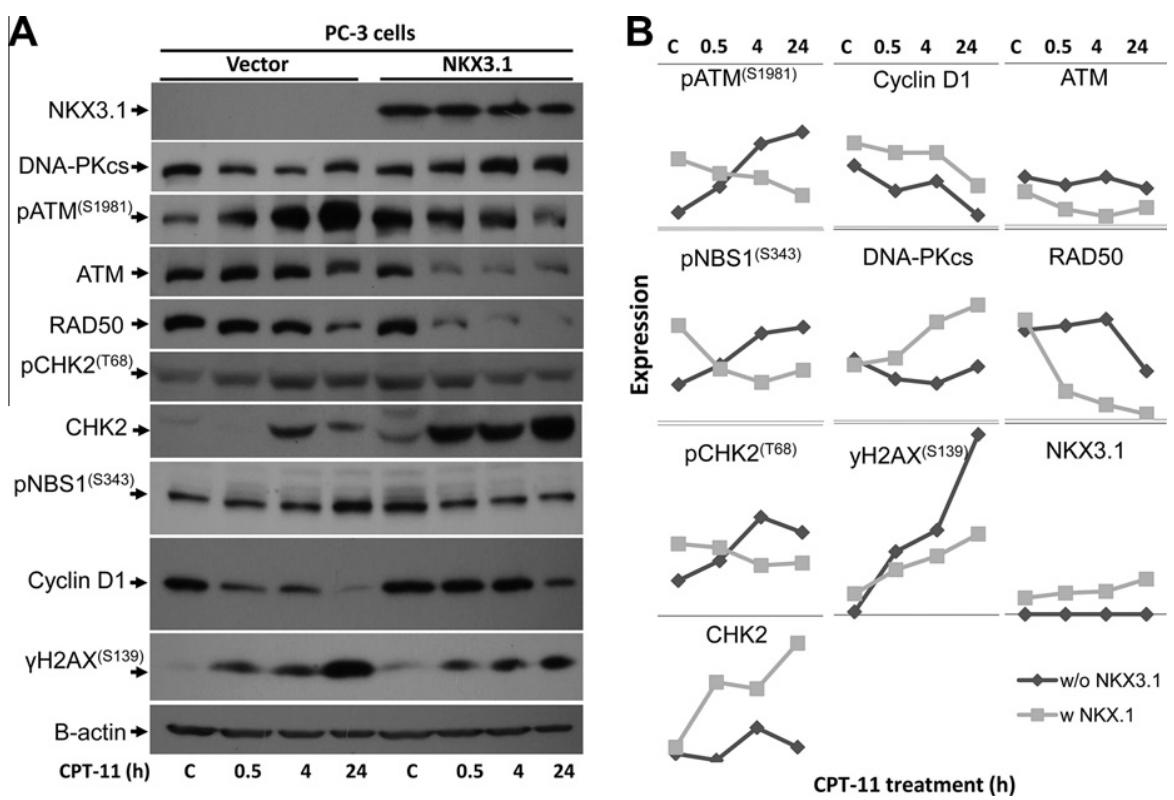

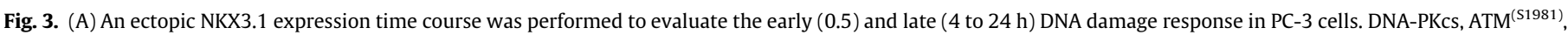

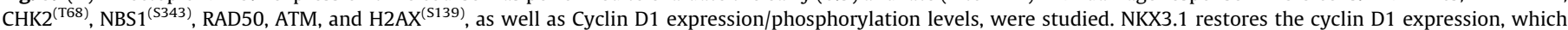
decreases after CPT-11 exposure. (B) Alterations in the expression of damage mediators are provided.

A
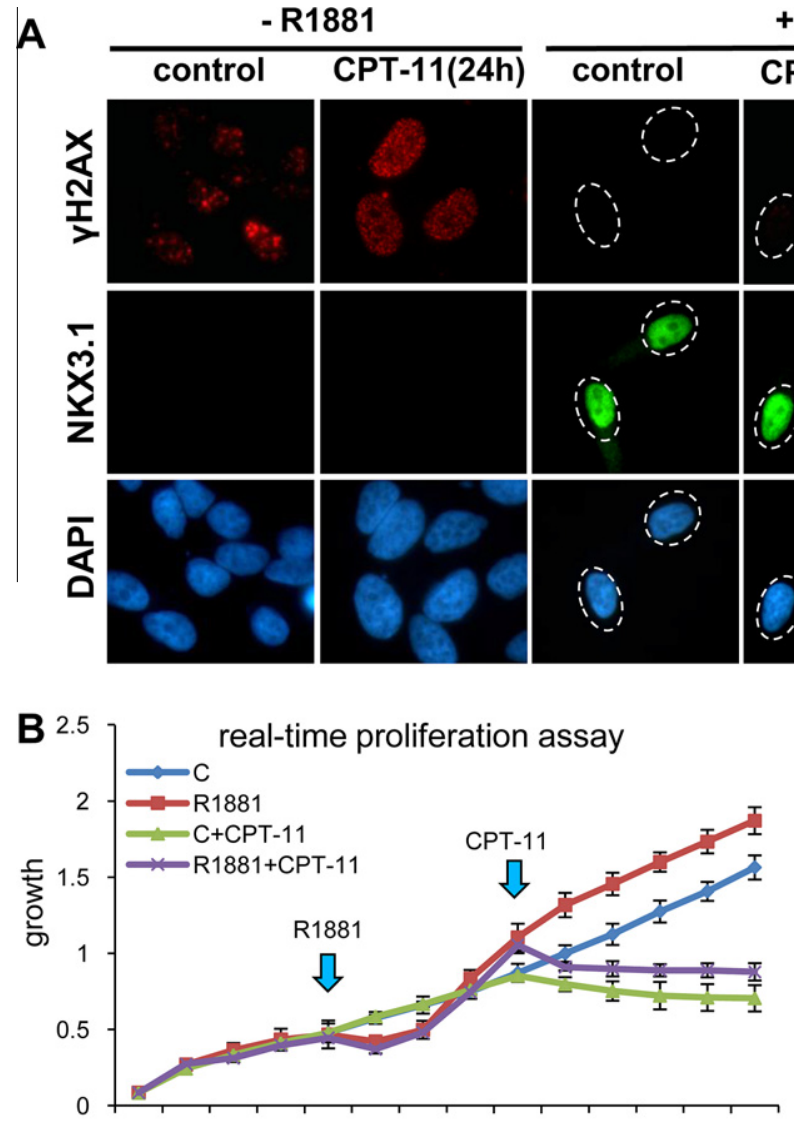

+ R1881

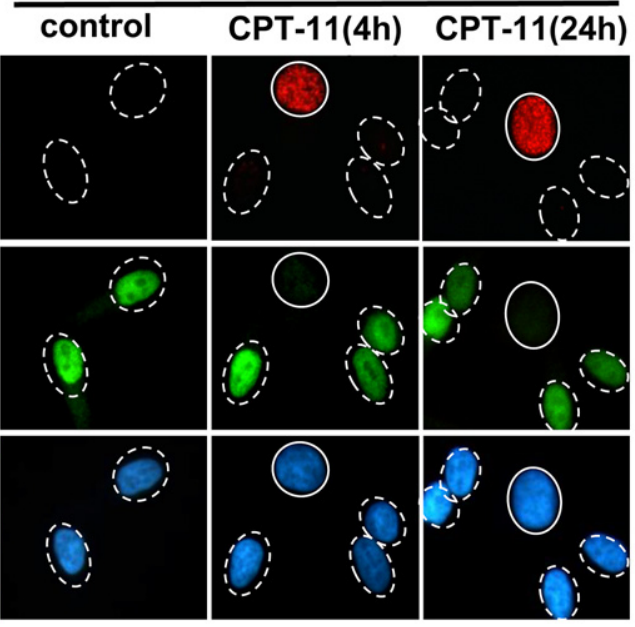

C

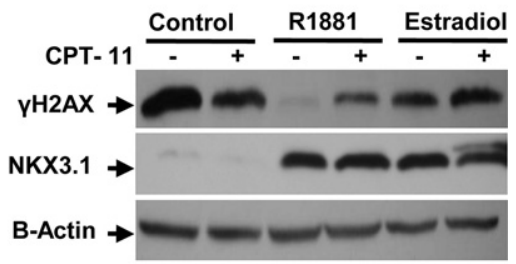

time (h) $0 \begin{array}{llllllllllllll}0 & 6 & 12 & 18 & 24 & 30 & 36 & 42 & 48 & 54 & 60 & 66 & 72 & 75\end{array}$

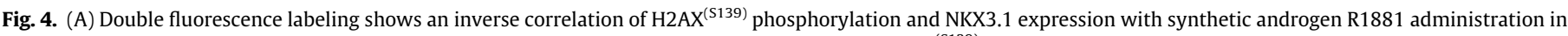

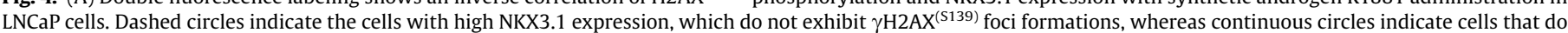

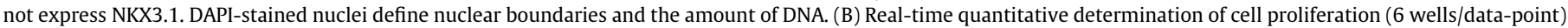

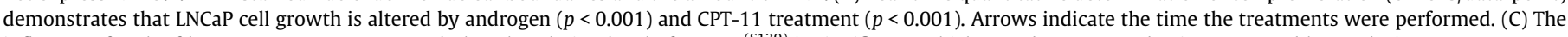
influence of $24 \mathrm{~h}$ of hormone treatment on total phosphorylation level of $\gamma \mathrm{H} 2 \mathrm{AX}{ }^{(\mathrm{S} 139)}$ is significant, which was demonstrated using western blot analysis. 
resulted in a slight change (Fig. 4C). This effect following estrogen treatment may be due to the mutant (T877A) androgen receptor LBD (ligand-binding domain), which accommodates different hormones in LNCaP cells $[25,26]$. Therefore, we concluded that treatment with androgen or estrogen either abrogates the phosphorylation via direct interaction or activates the DDR upon DNA damage putatively via a hormone-responsive factor.

Thus, NKX3.1 overexpression in PC-3 cells results in a distinct response to topo I inhibition, which was similar in LNCaP cells that can be induced with androgens. As it was previously reported that NKX3.1 repressed transcription together with the Groucho complex [11] and regulated the pro-oxidant enzyme expressions by HDAC1 recruitment [13], NKX3.1 may be the major regulator of transcription, cell cycle and repair in prostate cells [16,17,21,22].

In conclusion, NKX3.1-mediated activation of DDR restores the intra $S$ phase arrest upon DNA damage and, consequently, leads to reprogramming of the cells at the $\mathrm{G} 1 / \mathrm{S}$ phase transition. This process is controlled via an androgen action when the damage response is constitutive. Upon exposure to DNA damage, the role of NKX3.1 in DDR with direct interactions as well as its putative role in histone re-organization needs to be assessed in further studies.

\section{Acknowledgments}

We would like to thank Dr. Timur Kose (Ege University, Department of Biostatistics and Biometry) for his kind assistance with the statistical analysis, Dr. Fahri Saatcioglu (University of Oslo, Oslo, Norway) for providing constructs, deletion mutants and the rabbit polyclonal $\alpha$-NKX3.1 antibody, and Dr. Buket Kosova (Ege University, İzmir, Turkey) for the B-actin antibody. This research was supported with grants (TUBITAK-106S200, -110S134, COST action BM0703 CANGENIN (TUBITAK -108S288)) from the Turkish Scientific and Technological Research Council and BAP projects (06MUH004 and 10MUH006) by the Ege University to KSK.

\section{Appendix A. Supplementary data}

Supplementary data associated with this article can be found, in the online version, at doi:10.1016/j.bbrc.2011.09.035.

\section{References}

[1] C. Huggins, Endocrine-induced regression of cancers, Cancer Res. 27 (1967) 1925-1930.

[2] S.R. Denmeade, X.S. Lin, J.T. Isaacs, Role of programmed (apoptotic) cell death during the progression and therapy for prostate cancer, Prostate 28 (1996) 251-265.

[3] N. Bruchovsky, L.H. Klotz, M. Sadar, J.M. Crook, D. Hoffart, L. Godwin, M. Warkentin, M.E. Gleave, S.L. Goldenberg, Intermittent androgen suppression for prostate cancer: Canadian Prospective Trial and related observations, Mol. Urol. 4 (2000) 191-199. discussion 201.

[4] Z. Culig, H. Steiner, G. Bartsch, A. Hobisch, Mechanisms of endocrine therapyresponsive and -unresponsive prostate tumours, Endocr. Relat. Cancer 12 (2005) 229-244.

[5] T.H. Van der Kwast, J. Schalken, J.A. Ruizeveld de Winter, C.C. van Vroonhoven, E. Mulder, W. Boersma, J. Trapman, Androgen receptors in endocrine-therapyresistant human prostate cancer, Int. J. Cancer 48 (1991) 189-193.
[6] K.S. Korkmaz, C.G. Korkmaz, E. Ragnhildstveit, S. Kizildag, T.G. Pretlow, F. Saatcioglu, Full-length cDNA sequence and genomic organization of human NKX3A - alternative forms and regulation by both androgens and estrogens, Gene 260 (2000) 25-36.

[7] J.L. Prescott, L. Blok, D.J. Tindall, Isolation and androgen regulation of the human homeobox cDNA, NKX3.1, Prostate 35 (1998) 71-80.

[8] S.L. Zheng, J.H. Ju, B.L. Chang, E. Ortner, J. Sun, S.D. Isaacs, J. Sun, K.E. Wiley, W. Liu, M. Zemedkun, P.C. Walsh, J. Ferretti, J. Gruschus, W.B. Isaacs, E.P. Gelmann, $\mathrm{J}$. Xu, Germ-line mutation of NKX3.1 cosegregates with hereditary prostate cancer and alters the homeodomain structure and function, Cancer Res. 66 (2006) 69-77.

[9] Q. Lei, J. Jiao, L. Xin, C.J. Chang, S. Wang, J. Gao, M.E. Gleave, O.N. Witte, X. Liu, H. Wu, NKX3.1 stabilizes p53, inhibits AKT activation, and blocks prostate cancer initiation caused by PTEN loss, Cancer Cell 9 (2006) 367-378.

[10] R. Bhatia-Gaur, A.A. Donjacour, P.J. Sciavolino, M. Kim, N. Desai, P. Young, C.R. Norton, T. Gridley, R.D. Cardiff, G.R. Cunha, C. Abate-Shen, M.M. Shen, Roles for Nkx3.1 in prostate development and cancer, Genes Dev. 13 (1999) 966-977.

[11] C. Bowen, L. Bubendorf, H.J. Voeller, R. Slack, N. Willi, G. Sauter, T.C. Gasser, P. Koivisto, E.E. Lack, J. Kononen, O.P. Kallioniemi, E.P. Gelmann, Loss of NKX3.1 expression in human prostate cancers correlates with tumor progression, Cancer Res. 60 (2000) 6111-6115.

[12] B. Guan, P. Pungaliya, X. Li, C. Uquillas, L.N. Mutton, E.H. Rubin, C.J. Bieberich, Ubiquitination by TOPORS regulates the prostate tumor suppressor NKX3.1, J. Biol. Chem. 283 (2008) 4834-4840.

[13] X. Ouyang, T.L. DeWeese, W.G. Nelson, C. Abate-Shen, Loss-of-function of Nkx3.1 promotes increased oxidative damage in prostate carcinogenesis, Cancer Res. 65 (2005) 6773-6779.

[14] M.C. Markowski, C. Bowen, E.P. Gelmann, Inflammatory cytokines induce phosphorylation and ubiquitination of prostate suppressor protein NKX3.1, Cancer Res. 68 (2008) 6896-6901.

[15] C. Bowen, A. Stuart, J.H. Ju, J. Tuan, J. Blonder, T.P. Conrads, T.D. Veenstra, E.P. Gelmann, NKX3.1 homeodomain protein binds to topoisomerase I and enhances its activity, Cancer Res. 67 (2007) 455-464.

[16] G.L. Mayeur, W.-J. Kung, A. Martinez, C. Izumiya, D.J. Chen, H.-J. Kung, Ku Is a Novel Transcriptional Recycling Coactivator of the Androgen Receptor in Prostate Cancer Cells, J. Biol. Chem. 280 (2005) 10827-10833.

[17] C. Bowen, E.P. Gelmann, NKX3.1 activates cellular response to DNA damage, Cancer Res. 70 (2010) 3089-3097.

[18] C.G. Korkmaz, K.S. Korkmaz, J. Manola, Z. Xi, B. Risberg, H. Danielsen, J. Kung, W.R. Sellers, M. Loda, F. Saatcioglu, Analysis of androgen regulated homeobox gene NKX3.1 during prostate carcinogenesis, J. Urol. 172 (2004) 1134-1139.

[19] K.S. Korkmaz, C.G. Korkmaz, T.G. Pretlow, F. Saatcioglu, Distinctly different gene structure of KLK4/KLK-L1/prostase/ARM1 compared with other members of the kallikrein family: intracellular localization, alternative cDNA forms, and regulation by multiple hormones, DNA Cell Biol. 20 (2001) 435-445.

[20] Z. Cai, K.A. Vallis, R.M. Reilly, Computational analysis of the number, area and density of gamma-H2AX foci in breast cancer cells exposed to (111)In-DTPAhEGF or gamma-rays using Image-J software, Int. J. Radiat. Biol. 85 (2009) 262271.

[21] S. Hanasoge, M. Ljungman, H2AX phosphorylation after UV irradiation is triggered by DNA repair intermediates and is mediated by the ATR kinase, Carcinogenesis 28 (2007) 2298-2304.

[22] M.S. Huen, J. Chen, The DNA damage response pathways: at the crossroad of protein modifications, Cell Res. 18 (2008) 8-16.

[23] I. Rappold, K. Iwabuchi, T. Date, J. Chen, Tumor suppressor p53 binding protein 1 (53BP1) is involved in DNA damage-signaling pathways, J. Cell Biol. 153 (2001) 613-620.

[24] H. Tauchi, S. Matsuura, J. Kobayashi, S. Sakamoto, K. Komatsu, Nijmegen breakage syndrome gene, NBS1, and molecular links to factors for genome stability, Oncogene 21 (2002) 8967-8980.

[25] J. Tan, Y. Sharief, K.G. Hamil, C.W. Gregory, D.Y. Zang, M. Sar, P.H. Gumerlock R.W. deVere White, T.G. Pretlow, S.E. Harris, E.M. Wilson, J.L. Mohler, F.S. French, Dehydroepiandrosterone activates mutant androgen receptors expressed in the androgen-dependent human prostate cancer xenograft CWR22 and LNCaP cells, Mol. Endocrinol. 11 (1997) 450-459.

[26] S. Takahashi, T. Watanabe, M. Okada, K. Inoue, T. Ueda, I. Takada, T. Watabe, Y. Yamamoto, T. Fukuda, T. Nakamura, C. Akimoto, T. Fujimura, M. Hoshino, Y. Imai, D. Metzger, K. Miyazono, Y. Minami, P. Chambon, T. Kitamura, T. Matsumoto, S. Kato, Noncanonical Wht signaling mediates androgendependent tumor growth in a mouse model of prostate cancer, Proc Natl Acad Sci U S A 108 (2011) 4938-4943. 